\title{
Socioeconomic status and stomach cancer incidence in men: results from the Netherlands Cohort Study
}

\author{
A Jeanne $M$ van Loon, R Alexandra Goldbohm, Piet A van den Brandt
}

\begin{abstract}
Study objective-To study the association between socioeconomic status (SES) and stomach cancer incidence (cardia and non-cardia) and the role of lifestyle factors in explaining this association.

Design-Prospective cohort study on diet and cancer that started in 1986. Data were collected by means of a self administered questionnaire.

Setting-Population originating from 204 municipalities in the Netherlands.

Participants-58 279 men aged 55-69 years. After 4.3 years of follow up, 162 incident stomach cancer cases were detected (49 cardia and 113 non-cardia cases).

Main results and conclusions-After adjustment for age, a lower overall stomach cancer risk was found for men with the highest attained level of education (RR highest/lowest level $=0.54,95 \%$ CI 0.33 , 0.89 , trend, $p=0.02$ ). This association became less strong after additional adjustment for smoking, intake of vitamin $C, \beta$ carotene, alcohol and coffee, family history of stomach cancer, and history of stomach disorders $(\mathrm{RR}=0.61,95 \% \mathrm{CI} 0.34$, 1.07 , trend, $p=0.11)$. No clear association was found between occupation based SES indicators and stomach cancer risk. Analyses per subsite of stomach cancer revealed that for people with the highest level of education the age adjusted rate ratio for cardia cancer changed from 0.37 $(95 \% \mathrm{CI}=0.13,1.00)$ to $0.60(95 \% \mathrm{CI}=0.19$,
\end{abstract}

Maastricht University, Department of Epidemiology, Maastricht, the Netherlands A J $M$ van Loon R A Goldbohm P A van den Brandt

TNO-Toxicology and Nutrition Institute, Department of Nutrition, Zeist, the Netherlands R A Goldbohm

Correspondence to: Ms A J M van Loon, Maastricht University, Department of Epidemiology, POB 616 , $6200 \mathrm{MD}$ Maastricht, the Netherlands.

Accepted for publication 26 June 1997 cer, SES is not thought to be a direct risk factor. Some lifestyle variables that have been identified as possible risk factors for stomach cancer, for example, vitamin C intake, ${ }^{13} 14$ intake of $\beta$ carotene, ${ }^{13}$ alcohol consumption, ${ }^{15} 16$ and smoking habits, ${ }^{16}{ }^{17}$ are all characteristics associated with SES. ${ }^{18-20}$ Therefore, we examined the association between SES and stomach cancer incidence and the role of these lifestyle factors in explaining a possible association in the Netherlands Cohort Study (NLCS) on diet, other lifestyle variables, and cancer risk. Earlier research in the NLCS showed an association between coffee consumption and stomach cancer risk. ${ }^{21}$ Thus, coffee consumption is also included in the analyses. Moreover, adjustment is made for age, family history of stomach cancer, and prevalence of stomach disorders, because these factors may confound the association between SES and stomach cancer. $^{22}{ }^{23}$

There are strong indications that risk factors for stomach cancer differ between subsites. ${ }^{24}{ }^{25}$ Accordingly, we have studied the association between SES and stomach cancer more extensively by distinguishing cardia cancer from the more distal stomach cancers (non-cardia).

\section{Methods}

THE COHORT STUDY

In September 1986, the Netherlands Cohort Study (NLCS) investigating various lifestyle variables, sociodemographic indicators, and cancer risk was started. The cohort included 58279 men aged 55-69 years at the beginning of the study, originating from 204 municipalities in the Netherlands. Data were collected by means of a self administered questionnaire. A detailed description of the cohort study design has been reported elsewhere. ${ }^{26}$ For data analysis the case-cohort approach was used in which cases are derived from the entire cohort, while the person years at risk were estimated from a random sample of 1688 subjects (subcohort). After the baseline exposure measurement the subcohort has been followed up biennially for vital status information. In this period, no subcohort members were lost to follow up.

Follow up for incident cancer has been established by record linkage with all regional cancer registries in the Netherlands and with a national pathology register (PALGA). The method of record linkage has been described previously. ${ }^{27}$ The analysis is restricted to microscopically confirmed stomach cancer incidence (excluding lymphoma) in the period from September 1986 to December 1990. In 
Table 1 Distribution of SES indicators and potential confounders in male stomach cancer cases and subcohort

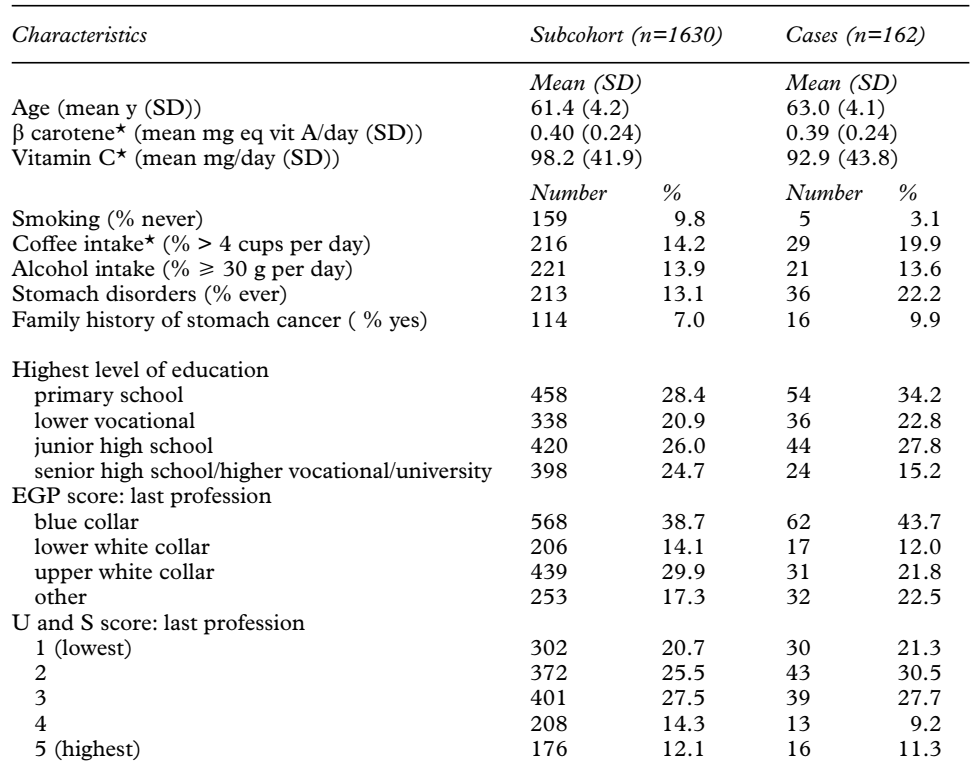

^Only subjects with complete dietary data (1525 subcohort members and 146 cases).

this period completeness of follow up of the cohort through linkage with the cancer registries and PALGA was estimated to be at least $96 \%{ }^{28}$ After excluding subjects with self reported prevalent cancer other than skin cancer 162 stomach cancer cases were detected; 49 cardia and 113 non-cardia cases. Prevalent cancer cases other than skin cancer were also excluded from the subcohort, leaving 1630 subjects available for analysis.

SOCIOECONOMIC STATUS

SES was measured by means of highest level of education attained and by means of occupational history, two of the recommended measures for SES. ${ }^{29}$ Educational level was classified as primary school, lower vocational school, junior high school, senior high school, higher vocational school, university and other education. Information about occupational history was coded according to the job coding system of the Central Bureau of Statistics (CBS) frequently used in the Netherlands. ${ }^{30}$ For the present analyses, these CBS codes were aggregated according to occupational sector and required training (EGP) and according to social standing (U and S). The EGP coding scheme is a reconstruction of the scheme developed by Erikson, Goldthorpe and Portocarero, ${ }^{31}$ which is still comparable with the original list. ${ }^{32}$ The $\mathrm{U}$ and $\mathrm{S}$ score is based on an ordering of occupational titles according to social standing and is also comparable with international classifications. ${ }^{33}$ Other factors possibly relevant to the association between SES and stomach cancer risk that were measured in the baseline questionnaire are age, smoking habits, alcohol intake, coffee consumption, intake of vitamin $C$ and $\beta$ carotene, the prevalence of stomach disorders (any stomach disease in the past that required medical attention), and family history of stomach cancer.
DATA ANALYSIS

The distribution of SES indicators and potential confounders known to be associated with SES and stomach cancer was compared between the case and subcohort group. Educational level was aggregated into four categories: primary school, lower vocational school, junior high school and senior high school, higher vocational school or university. The EGP score of the most recent occupation was divided into four categories: blue collar jobs (lower grade technicians, semi and unskilled manual workers), lower white collar jobs (administrators and non-manual employees), upper white collar jobs (professionals) and other (farmers and self employed people). The U and S score (also based on the last occupation) was divided into five categories increasing from low (for example, garbage collector) to high social standing (for example, lawyers).

To study the association between SES and stomach cancer risk and the role of possible confounders, data were analysed according to the case-cohort approach, ${ }^{34}{ }^{35}$ using the GLIM statistical package. ${ }^{36}$ Mantel-Haenszel rate ratios of stomach cancer were determined for each of the SES indicators, stratified for age. In the multivariate analyses, rate ratios and $95 \%$ confidence intervals of stomach cancer were computed for the different SES indicators, after adjustment for the covariates mentioned above. Recent research has pointed out that there seem to be aetiological differences between cardia cancer and the more distal stomach cancers. ${ }^{24}{ }^{25}$ Therefore, we have also determined Mantel-Haenszel rate ratios of cardia cancer (ICD-O topography 151.0) and non-cardia cancer (ICD-O 151.1-151.9) for one SES indicator. Subsequently, multivariate analyses were conducted for these subsites.

\section{Results}

Table 1 shows the distribution of SES indicators and covariates in the group of cases and the subcohort. Cases were on average older than members of the subcohort (mean age for cases is 63.0 years and for subcohort members 61.4 years). There was no substantial difference in the intake of $\beta$ carotene between cases and the subcohort members, but the dietary intake of vitamin C was for cases somewhat lower compared with subcohort members. There were more non-smokers among subcohort members compared with cases and proportionally more cases consumed large amounts of coffee ( $>4$ cups per day) than subcohort members. There were no differences in alcohol intake between cases and subcohort members. Stomach disorders were more prevalent among cases compared with members of the subcohort. The same was found with regard to family history of stomach cancer. The association between the various SES indicators and stomach cancer incidence is consistent: in the case group there were proportionally more men with a lower level of education, a blue collar job and a low $U$ and $S$ score (social standing) compared with the subcohort.

The association between SES indicators and covariates was studied in the subcohort (table 
Table 2 Association between possible confounders and SES indicators in the subcohort

\begin{tabular}{|c|c|c|c|c|c|c|c|c|}
\hline \multirow[b]{2}{*}{ Characteristic } & \multicolumn{3}{|c|}{ Highest level of education * } & \multicolumn{3}{|l|}{$E G P$} & \multicolumn{2}{|c|}{$U$ and $S$} \\
\hline & Low & Medium & High & Blue collar & $\begin{array}{l}\text { White } \\
\text { collart }\end{array}$ & Other & Low $\neq$ & High \\
\hline Age (mean y) & 61.9 & 61.3 & 61.1 & 61.3 & 61.1 & 61.8 & 61.4 & 61.2 \\
\hline$\beta$ carotene $\int$ (mean mg eq vit $\mathrm{A} /$ day) & 0.40 & 0.40 & 0.41 & 0.41 & 0.41 & 0.41 & 0.42 & 0.40 \\
\hline Vitamin $\mathrm{C} \int$ (mean $\mathrm{mg} /$ day) & 92.4 & 100.0 & 101.0 & 97.1 & 102.0 & 95.6 & 97.0 & 100.9 \\
\hline Smoking (\% never) & 9.2 & 9.9 & 10.3 & 7.4 & 10.4 & 12.6 & 10.5 & 8.5 \\
\hline Coffee intake $\$(\%>4$ cups per day) & 19.6 & 14.9 & 6.9 & 20.3 & 9.4 & 11.3 & 17.9 & 10.7 \\
\hline Acohol intake $(\% \geqslant 30$ g per day) & 9.1 & 12.5 & 22.2 & 10.6 & 20.6 & 11.8 & 10.8 & 16.7 \\
\hline Stomach disorders (\% ever) & 15.3 & 13.5 & 9.8 & 15.1 & 9.6 & 15.0 & 16.8 & 9.2 \\
\hline Family history of stomach cancer (\% yes) & 7.0 & 7.1 & 7.0 & 8.1 & 6.8 & 5.9 & 7.1 & 7.3 \\
\hline
\end{tabular}

^Highest level of education: low = primary school; medium = lower vocational or junior high school; high = senior high school, higher vocational or university.

†White collar = lower white collar or upper white collar.

$\neq$ Low social standing: $\mathrm{U}$ and $\mathrm{S}$ categories 1 and 2; high social standing: $\mathrm{U}$ and $\mathrm{S}$ categories 3,4 and 5 .

SOnly subjects with complete dietary data.

2). SES was inversely related to age. The mean intake of $\beta$ carotene did not differ among the SES categories, whereas the mean intake of vitamin $C$ was higher in the highest SES categories. The proportion of men who never smoked was somewhat higher among men with a high level of education or a white collar profession. Proportionally more men with a low SES consumed large amounts of coffee $(>4$ cups per day), whereas proportionally more men with a high SES consumed large amounts of alcohol ( $\geqslant 30 \mathrm{~g}$ per day). The prevalence of stomach disorders was higher among the lower SES categories and there was no substantial difference in family history of stomach cancer among SES categories.

Table 3 gives the results of the stratified analyses. After adjustment for age in three five year categories, there was a statistically significant inverse association between level of education and stomach cancer risk ( $R R$ highest/lowest level of education $=0.54$; $95 \%$ CI 0.33, 0.89; trend, $\mathrm{p}=0.02$ ) and a statistically non-significant inverse association between EGP score and stomach cancer risk (RR upper white collar/blue collar $=0.67 ; 95 \% \mathrm{CI}$ $0.42,1.04$; trend, $\mathrm{p}=0.07)$. There was no clear association between $\mathrm{U}$ and $\mathrm{S}$ score and stomach cancer risk (RR high/low social standing $=0.99 ; 95 \%$ CI 0.52, 1.85; trend, $\mathrm{p}=0.34$ ).
To find out whether an association between the SES indicators and stomach cancer risk resulted from lifestyle characteristics, additional adjustment was made for smoking, alcohol intake, coffee intake, vitamin $C, \beta$ carotene, stomach disorders, and family history of stomach cancer (table 3). After that adjustment there was still an inverse association between level of education and stomach cancer risk (RR highest $/$ lowest level of education $=0.61 ; 95 \%$ CI $0.34,1.07$ ), but the test for trend was not statistically significant any more (trend, $\mathrm{p}=$ 0.11 ). The association between EGP score and stomach cancer risk also became less prominent (RR upper white collar/blue collar $=0.76$; 95\% CI $0.45,1.28$; trend, $\mathrm{p}=0.21$ ), and there was still no association between $\mathrm{U}$ and $\mathrm{S}$ score and stomach cancer risk.

We have studied the association between level of education and stomach cancer more extensively by distinguishing cardia cancer from non-cardia cancer. Table 4 gives the results of the stratified analyses and multivariate analyses. Men with a higher level of education had a lower age adjusted risk for cardia cancer compared with men with a lower level of education (RR highest/lowest level of education $=0.37 ; 95 \%$ CI $0.13,1.00)$. On the other hand, men with lower vocational school or junior high school had an age adjusted rate ratio

Table 3 Age adjusted Mantel-Haenszel rate ratios and multivariate ${ }^{\star}$ rate ratios for stomach cancer according to three different SES indicators

\begin{tabular}{|c|c|c|c|c|}
\hline SES indicators & $\begin{array}{l}\text { No of cases } \\
\text { in cohort }\end{array}$ & $\begin{array}{l}\text { Person years in } \\
\text { subcohort }\end{array}$ & $R R_{M H}(95 \% C I)$ & $\begin{array}{l}\text { RR }(95 \% C I) \\
\text { multivariate* }\end{array}$ \\
\hline \multicolumn{5}{|l|}{ Highest level of education } \\
\hline primary school & 54 & 1888 & $1^{\dagger}$ & $1^{\dagger}$ \\
\hline lower vocational & 36 & 1426 & $0.94(0.60,1.47)$ & $0.81(0.48,1.38)$ \\
\hline junior high school & 44 & 1754 & $0.93(0.60,1.43)$ & $0.90(0.56,1.45)$ \\
\hline senior high school/higher vocational/university & 24 & 1655 & $0.54(0.33,0.89)$ & $0.61(0.34,1.07)$ \\
\hline Test for trend $\chi^{2}$ ( $\mathrm{p}$ value) & & & $5.19(0.02)$ & $2.50(0.11)$ \\
\hline \multicolumn{5}{|l|}{ EGP score: last profession } \\
\hline blue collar & 62 & 2361 & $1+$ & $1+$ \\
\hline lower white collar & 17 & 863 & $0.74(0.42,1.30)$ & $0.80(0.43,1.49)$ \\
\hline upper white collar & 31 & 1831 & $0.67(0.42,1.04)$ & $0.76(0.45,1.28)$ \\
\hline otherł & 32 & 1062 & $1.11(0.70,1.74)$ & $1.16(0.69,1.95)$ \\
\hline Test for trend $\chi^{2}$ ( $\mathrm{p}$ value) & & & $3.35(0.07)$ & $1.57(0.21)$ \\
\hline \multicolumn{5}{|l|}{$\mathrm{U}$ and $\mathrm{S}$ score: last profession } \\
\hline 1 (lowest) & 30 & 1264 & $1 \dagger$ & $1 \dagger$ \\
\hline 2 & 43 & 1554 & $1.17(0.71,1.92)$ & $1.46(0.82,2.59)$ \\
\hline 3 & 39 & 1668 & $1.00(0.60,1.64)$ & $1.18(0.65,2.14)$ \\
\hline 4 & 13 & 869 & $0.64(0.33,1.27)$ & $0.95(0.44,2.07)$ \\
\hline 5 (highest) & 16 & 736 & $0.99(0.52,1.85)$ & $1.36(0.61,3.04)$ \\
\hline Test for trend $\chi^{2}$ ( $\mathrm{p}$ value) & & & $0.92(0.34)$ & $0.03(0.86)$ \\
\hline
\end{tabular}

†Reference category.

${ }^{\star}$ Multivariate analyses with adjustment for age, smoking, alcohol intake, coffee intake, intake of vitamin C, $\beta$ carotene, family history of stomach cancer, and stomach disorders.

†Excluded for test for trend. 
Table 4 Age adjusted Mantel-Haenszel rate ratios and multivariate ${ }^{\star}$ rate ratios for cardia cancer and other subsites of stomach cancer according to highest level of education

\begin{tabular}{|c|c|c|c|c|}
\hline Highest level of education & $\begin{array}{l}\text { No of cases } \\
\text { in cohort }\end{array}$ & $\begin{array}{l}\text { Person years in } \\
\text { subcohort }\end{array}$ & $R R_{M H}(95 \% C I)$ & $\begin{array}{l}R R(95 \% C I) \\
\text { multivariate }\end{array}$ \\
\hline \multicolumn{5}{|l|}{ Cardia cancer } \\
\hline primary school & 15 & 1888 & $1 \dagger$ & $1 \dagger$ \\
\hline lower vocational & 12 & 1426 & $1.03(0.48,2.21)$ & $1.30(0.53,3.19)$ \\
\hline junior high school & 16 & 1754 & $1.17(0.57,2.38)$ & $1.33(0.56,3.14)$ \\
\hline senior high school/higher vocational/university & 5 & 1655 & $0.37(0.13,1.00)$ & $0.60(0.19,1.87)$ \\
\hline Test for trend $\chi^{2}$ ( $\mathrm{p}$ value) & & & $2.56(0.10)$ & $0.35(0.55)$ \\
\hline \multicolumn{5}{|l|}{ Other subsites of stomach cancer } \\
\hline primary school & 39 & 1888 & $1 \dagger$ & $1 \dagger$ \\
\hline lower vocational & 24 & 1426 & $0.88(0.51,1.49)$ & $0.63(0.34,1.19)$ \\
\hline junior high school & 28 & 1754 & $0.86(0.52,1.43)$ & $0.77(0.45,1.34)$ \\
\hline senior high school/higher vocational/university & 19 & 1655 & $0.59(0.33,1.05)$ & $0.58(0.31,1.11)$ \\
\hline Test for trend $\chi^{2}$ ( $\mathrm{p}$ value) & & & $3.08(0.08)$ & $2.54(0.11)$ \\
\hline
\end{tabular}

*Multivariate analyses with adjustment for age, smoking, alcohol intake, coffee intake, intake of vitamin C, $\beta$ carotene, family history of stomach cancer, and stomach disorders.

$\dagger$ Reference category.

greater than one, compared with men with primary school. After additional adjustment for lifestyle variables mentioned above the rate ratios for cardia cancer changed considerably. However, people with a higher level of education still had a non-significant lower risk for cardia cancer than people with a lower level of education (RR highest/lowest level of education $=0.60 ; 95 \%$ CI $0.19,1.87$ ).

After adjustment for age, there was a non-significant inverse association between level of education and the risk of non-cardia cancer $(\mathrm{RR}$ highest/lowest level of education = $0.59 ; 95 \%$ CI $0.33,1.05)$. This inverse association changed very little after additional adjustment for lifestyle variables (RR highest/lowest level of education $=0.58 ; 95 \%$ CI $0.31,1.11$ ) . This is in contrast with the results from the association between SES and cardia cancer risk.

\section{Discussion}

We have found an inverse association between level of education and stomach cancer risk. This association became less apparent when adjustment was made for various lifestyle variables, indicating that part of the higher risk for stomach cancer for people with a low level of education may be because of lifestyle characteristics. The association between the occupation based SES indicators and stomach cancer risk was less clear. Both for cardia cancer as well as for non-cardia cancer a nonsignificantly inverse association with level of education was observed. Adjustment for potential risk factors for stomach cancer showed different results: the lower cardia cancer risk for people with the highest level of education changed noticeably after adjustment, while the inverse association between level of education and non-cardia cancer changed very little after additional adjustment.

The significant inverse association between level of education and stomach cancer risk for men seen in our study is comparable with results from cross sectional, ${ }^{2}$ casecontrol, ${ }^{391012}$ and cohort studies. ${ }^{78}$ From the six studies ${ }^{34-812}$ in which occupation was used as SES indicator, four found a significant inverse association. ${ }^{36812}$ In one case-control study ${ }^{4}$ a non-significant inverse association was reported, while a cohort study showed no clear association. ${ }^{7}$ In the latter the incidence of stomach cancer among managerial and clerical workers was significantly lower compared with the stomach cancer risk in the whole population, but unskilled workers did not have a significantly higher risk. In four studies lifestyle characteristics such as smoking, ${ }^{2-4}$ alcohol consumption $^{3}$ or vegetable consumption ${ }^{12}$ were included. Overall, adjustment for these factors did not dramatically change the association between SES and stomach cancer risk. Although in one case-control study, ${ }^{12}$ where adjustment was made for age, sex, vegetable consumption, body mass index at age 20 , age at first access to refrigerator, and number of siblings, the risk estimates in relation to occupation and duration of education had a tendency to approach unity. Nevertheless, there was still a significant inverse association between education and stomach cancer risk.

We found three studies that described the association between SES and stomach cancer, which made a distinction between cardia cancer and the more distal stomach cancers. ${ }^{243738}$ One study examined incidence trends in oesophageal and gastric cancer in the UK, during 1962 to 1981. The authors reported that in the higher SES groups there were more cardia cases and less pyloric cases recorded than expected and in the lower SES groups there were less cardia cases and more pyloric antrum cases. ${ }^{24}$ Another study evaluated risk factors for cancers of the cardia and more distal sites, in white men under the age of 55 years. ${ }^{37}$ They found no association between level of education and cardia cancer, whereas level of education was strongly associated with the more distal stomach cancers. However, in this case-control study age and sex matched neighbourhood controls were used. As there is an association between SES and neighbourhood, ${ }^{39}$ the control group seems not entirely appropriate for studying SES and cancer. The third study ${ }^{38}$ reported both for cardia cancer and for other subsites a decreased risk with increasing social class (based on a combination of occupation and education).

In our study both cardia cancer and non-cardia cancer showed a non-significant inverse association with level of education, although the lower cardia cancer risk was only found among people with senior high school, 
KEY POINTS

- There is an inverse association between level of education and stomach cancer risk.

- Part of the inverse association between education and stomach cancer is due to lifestyle.

- It is relevant to distinguish cardia cancer from the more distal stomach cancers when studying the association with socioeconomic status.

higher vocational school or university. Adjustment for potential risk factors, including lifestyle variables showed different results for cardia and non-cardia cancer. Cardia cancer is found to be aetiologically more related to carcinoma of the distal oesophagus than to distal gastric cancers. ${ }^{22}$ This indicates that risk factors for cardia cancer may differ from risk factors for non-cardia cancer. Several studies have investigated this hypothesis ${ }^{37} 3840$ with varying results. One study reported no difference in cigarette and alcohol use between patients with "esophagocardia" cancer and patients with stomach cancer not involving the cardia. ${ }^{40}$ Nevertheless, it seems that if there is a positive association between smoking and stomach cancer, it is thought for both cardia cancer as well as for non-cardia cancer. ${ }^{37}{ }^{41} \mathrm{On}$ the other hand, if there is a positive association found between alcohol use and stomach cancer, this only seems to apply to cardia cancer. ${ }^{373841}$ Furthermore, there are indications that a joint effect of alcohol drinking and smoking may play an important part in the development of gastric cancer, especially of cardia cancer. ${ }^{41}$

The cohort study has been performed in a large sample of the general population aged 55-69 years at baseline. The follow up period of 4.3 years resulted in 162 male stomach cancer cases, indicating that the study had reasonable but not very large power. Moreover, when distinction was made between cardia cancer and non-cardia cancer respectively 49 and 113 cases were available for analysis. The follow up of person years was $100 \%$ complete and the completeness of cancer follow up was also very high, showing that selection bias resulting from loss to follow up is unlikely. Although known risk factors for stomach cancer were measured and controlled for in the multivariate analyses, residual confounding could still have existed. Besides, we had no information about the prevalence of Helicobacter pylori infection, which may be an important risk factor for stomach cancer, ${ }^{42}$ especially for non-cardia cancer $^{43}$ and is known to be associated with SES..$^{44}$

Another fact that could have influenced the results is misclassification of exposure. SES is operationalised as highest level of education, EGP score (functional level), and $\mathrm{U}$ and $\mathrm{S}$ score (social standing), both based on the last occupation. Highest level of education is a characteristic that is easily obtainable and recordable. It applies to every adult person and in people it is stable over time. This stability has also negative implications for the suitability of level of education as SES indicator, because it can mask important changes in individual circumstances after education is completed. ${ }^{45}$ Therefore highest level of education is probably a less relevant SES indicator for the older generation. ${ }^{46}$ The occupation based SES indicators reflect the more recent situation, but occupational status as SES indicator leads to the problem how to classify persons without formal occupation. Because we used occupation as an indicator of SES, it seems reasonable to take the most recent occupation instead of the occupation performed the longest. Also for pensioners, a relatively large part of the study population, the most recent occupation is used.

In conclusion, we found an inverse age adjusted association between stomach cancer risk and highest level of education for men. This association became less apparent after additional adjustment for smoking, alcohol intake, coffee intake, intake of vitamin $C, \beta$ carotene, family history of stomach cancer, and stomach disorders. None of these lifestyle factors, however, explains the association between SES and stomach cancer risk on its own. The association between the occupation based SES indicators and stomach cancer risk was less clear. Nevertheless, the number of cases in our study is quite small. Therefore, a longer follow up time is required. When distinction was made between cardia and non-cardia cancer, it became evident that, although both cardia and non-cardia cancer showed an inverse association with level of education, adjustment for other risk factors reduced the association with cardia cancer but did not effect the association with non-cardia cancer.

We want to thank the participants in this study, the regional cancer registries (IKA, IKL, IKMN, IKN, IKO, IKR, IKST, IKW, IKZ), PALGA for providing incidence data; E Dorant, $S$ van de Crommert, $H$ Brants, P Florax, J Nelissen, $M$ Moll, and W van Dijk for assistance in the cohort study, E Dorant for useful comments on this manuscript and $\mathrm{S}$ van den Heuvel from the TNO-PG institute for coding the questions about occupation.

Funding: The Netherlands Cohort Study was financially supported by the Dutch Cancer Society.

Conflicts of interest: none.

1 Baquet CR, Horm JW, Gibbs T, Greenwald P. Socioeconomic factors and cancer incidence among blacks and whites. F Natl Cancer Inst 1991;83:551-7.

2 Williams RR, Horm JW. Association of cancer sites with tobacco and alcohol consumption and socioeconomic status of patients: interview study from the third national status of patients: interview study from the third

3 Ferraroni M, Negri E, La Vecchia CL, D'Avanzo B, FrancFerraroni M, Negri E, La Vecchia CL, D'Avanzo B, Franc-
eschi S. Socioeconomic indicators, tobacco and alcohol in eschi S. Socioeconomic indicators, tobacco and alcohol in
the aetiology of digestive tract neoplasms. Int 7 Epidemiol the aetiology of dige

4 Dockerty JD, Marshall S, Fraser J, Pearce N. Stomach cancer in new Zealand: time trends, ethnic group differences and a cancer registry-based case-control study. Int $\mathcal{F}$ Epidemiol 1991;20:45-53

5 Cuello C, Correa P, Haenszel W. Socio-economic class differences in cancer incidence in Cali, Colombia. Int $\mathcal{F}$ Cancer 1982;29:637-43

6 Vågerö D, Persson G. Occurrence of cancer in socioeconomic groups in Sweden. Scand F Soc Med 1986;14:151-60.

7 Pukkala E, Teppo L. Socioeconomic status and education as risk determinants of gastrointestinal cancer. Prev Med 1986;15:127-38.

8 Leon DA. Longitudinal study. Social distribution of cancer, 1971-1975 (OPCS Series LS No. 3). London: HMSO, 1988 .

9 Choi SY, Kahyo H. Effect of cigarette smoking and alcohol consumption in the etiology of cancers of the digestive tract. Int $\mathcal{F}$ Cancer 1991;49:381-6. 
10 Jedrychowski W, Wahrendorf J, Popiela T, Rachtan J. A case-control study of dietary factors and stomach cancer case-control study of dietary factors and stom
risk in Poland. Int 7 Cancer 1986;37:837-42.

11 Williams J, Clifford C, Hopper J, Giles G. Socioeconomic status and cancer mortality and incidence in Melbourne. Eur $\mathcal{F}$ Cancer 1991;27:917-21.

12 Hansson L-E, Baron J, Nyrén O, Bergström R, Wolk A, Lindgren A, Adami H-O. Early-life indicators of gastric cancer. A population-based case-control study in Sweden. Int $\mathcal{F}$ Cancer 1994;57:32-7.

13 Cipriani F, Buiatti E, Palli D. Gastric cancer in Italy. Ital f Gastroenterol 1991; 23:429-35.

14 Trichopoulos D, Ouranos G, Day N E, Tzonou A Manousos O, Papadimitriou Ch, Trichopoulos A. Diet and cancer of the stomach: A case-control study in Greece. Int f Cancer 1985:36:291-7.

15 Hoey J, Montvernay C, Lambert R. Wine and tobacco: risk factors for gastric cancer in France. Am $\mathcal{F}$ Epidemiol factors for gastric

16 De Stefani R, Correa P, Fierro L, Carzoglio J, DeneoPellegrini H, Zavala D. Alcohol drinking and tobacco
smoking in gastric cancer. A case-control study. Rev Epidesmoking in gastric cancer. A case-con
miol Sante Publique 1990;38;297-307.

17 Hansson L-E, Baron J, Nyrén O, Bergström R, Wolk A Adami H-O. Tobacco, alcohol and the risk of gastric cancer. A population-based case-control study in Sweden. Int $\mathcal{f}$ Cancer 1994;57:26-31.

18 Block G, Sorenson A. Vitamin C intake and dietary sources by demographic characteristics. Nutr Cancer 1987;10:53-65.

19 Hulshof KFAM, Löwik MRH, Kok FJ, Wedel M Kistemaker C, Brants HAM. Invloed van sociaaleconomische status op voeding en andere levensstijlfactoren. In: Mackenbach JP,ed. Sociaal-economische gezondheidsverschillen onderzocht, III. Den Haag: DOP, 1991.

20 Sterling TD, Weinkam JJ. Smoking patterns by occupation, industry, sex, and race. Arch Environ Health 1978;37:31317.

21 Goldbohm RA, Hertog MGL, Brants HAM, Van Poppel G, Van den Brandt PA. Consumption of black tea and cancer Van den Brandt PA. Consumption of black tea and cancer
risk: a prospective cohort study. $\mathcal{F}$ Natl Cancer Inst 1996;88: risk: a prost

22 Palli D, Galli M, Caporaso NE, et al. Family history and risk of stomach cancer in Italy. Cancer Epidemiol Biomarkers Prev 1994;3:15-18.

23 La Vecchia C, Negri E, Franceschi S, Gentile A. Family history and the risk for stomach and colorectal cancer. Cancer 1992;70:50-5.

24 Powell J, McConkey CC. Increasing incidence of adenocarcinoma of the gastric cardia and adjacent sites. Br 7 Cancer $1990 ; 62 ; 440-3$

25 Yang PC, Davis S. Epidemiological characteristics of adenocarcinoma of the gastric cardia and distal stomach in the United States, 1973-1982. Int f Epidemiol 1991;17:293-7.

26 Van den Brandt PA, Goldbohm RA, Van't Veer P, Volovics A, Hermus RJJ, Sturmans F. A large-scale prospective cohort study on diet and cancer in the Netherlands. F Clin Epidemiol 1990;43:285-95.

27 Van den Brandt PA, Schouten LJ, Goldbohm RA, Dorant E, Hunen PMH. Development of a record linkage protocol for use in the Dutch cancer registry for epidemiological research. Int 7 Epidemiol 1990;19:553-8.

28 Goldbohm RA, Van den Brandt PA, Dorant E. Estimation of the coverage of Dutch municipalities by cancer registries and PALGA based on hospital discharge data. Tijdschr Soc Gezondheidsz 1994;72:80-4.

29 Liberatos P, Link BG, Kelsey JL. The measurement of social class in epidemiology. Epidemiol Rev 1988;10:87-121.

30 Centraal Bureau voor de Statistiek. Beroepenclassificatie 1984. Lijst van benamingen per beroepencode. Voorburg: CBS, 1985.

31 Erikson R, Goldthorpe JH, Portocarero L. Intergenerational class mobility in three European societies: England, France and Sweden. Br f Sociol 1979;30:415-41.

32 Ganzeboom H, Luilkx R, Dessens J, De Graaf P, De Graaf $\mathrm{ND}$, Jansen W, Ultee W. Intergenerationele klassenmo$\mathrm{ND}$, Jansen W, Ultee W. Intergenerationele klassenmoMaatschappij 1987;62;17-43.

33 Van Berkel-Van Schaik A B, Tax B. Naar een standaardoperationalisatie van sociaal-economische status voor epidemiologisch en sociaal-medisch onderzoek. Sociaal-economische gezondheidsverschillen nr6. Den Haag: DOP, 1990.

34 Prentice RL. A case-cohort design for epidemiologic cohort studies and disease prevention trials. Biometrika 1986;73: $1-11$.

35 Van den Brandt PA, Van't Veer P, Goldbohm RA, et al. A prospective cohort study on dietary fat and the risk of postprospective cohort study on dietary fat and the risk of post-

36 Baker RJ. Glim 3.77. Reference Manual. Oxford: Numerical Algorithms Group, 1985.

37 Wu-Williams AH, Yu MC, Mack TM. Life-style, workplace, and stomach cancer by subsite in young men of Los Angeles county. Cancer Res 1990;50:2569-76.

38 Palli D, Bianchi S, Decarli A, et al. A case-control study of cancers of the gastric cardia in Italy. $\mathrm{Br} f$ Cancer 1992;65:263-6.

39 Stolwijk AM, Raat H. Sociaal-economische status. Het begrip, de meting en de classificatie in epidemiologisch onderzoek. Rotterdam: GGD, 1990.

40 Gray JR, Coldman AJ, MacDonald WC. Cigarette and alcohol use in patients with adenocarcinoma of the gastric cardia or lower esophagus. Cancer 1992;69:2227-31.

41 Inoue M, Tajima K, Hirose K, Kuroishi T, Gao C-M, Kitoh T. Life-style and subsite of gastric cancer - joint effect of
smoking and drinking habits. Int $\mathcal{F}$ Cancer 1994;56:494-9. 42 Forman D, Newell DG, Fullerton F, et al. Association between infection with Helicobacter pylori and risk of gastric cancer: evidence from a prospective investigation. $B M \mathcal{F}$ 1991;302:1302-5

43 Parsonnet J. Helicobacter pylori and gastric cancer. Gastroenterol Clin North Am 1993;22:89-105.

44 Taylor DN, Blaser MJ. The epidemiology of helicobacter pylori infection. Epidemiol Rev 1991;13:42-59.

45 Zurayk H, Halabi S, Deeb M. Measures of social class based on education for use in health studies in developing countries. F Epidemiol Community Health 1987;41:173-9.

46 Thijssen LJM. Sociale stratificatie onder ouderen. Sociaalcultureel Kwartaalbericht 1986;8:10-27. 